\title{
Number of Early Resorptions
}

National Cancer Institute

\section{Source}

National Cancer Institute. Number of Early Resorptions. NCI Thesaurus. Code C124635.

A measurement of the number of early resorptions in the uterus. 